\title{
Design of Personnel Management Information System Based on Cloud Computing
}

\author{
YANG Yuan-yuan $^{1,2}$, SHU Ming-lei ${ }^{1,2}$, WEI Nuo ${ }^{1,2}$ \\ ${ }^{1}$ Shandong Provincial Key Laboratory of Computer Networks \\ ${ }^{2}$ Shandong Computer Science Center (National Supercomputer Center in Jinan) \\ Jinan, China \\ yangyuany@sdas.org
}

\begin{abstract}
Personnel data information is an important part of personnel management digital process, personnel data as the underlying data source, provide the basic data for the other subsystems. With combination of ASP.NET and Microsoft SQL Server 2005, personnel management system was developed, which can improve the efficiency of personnel management, achieve the data sharing.
\end{abstract}

Keywords-Cloud Computing; Personnel Management; ASP.NET; ADO.NET; business logic layer; data access layer

\section{INTRODUCTION}

People use the traditional artificial way to carry on the personnel archives management all the time, the traditional methods have various shortcomings, such as heavy workload, low efficiency, poor security, also over time, which will produce a large number of documents and data, and has brought a lot of difficulties to searching, updating and maintenance. With the continuous development of science and technology, computer science is already gradually mature, its powerful features have been recognized by people, and has entered the human society in various fields and is playing an important role. The use of computer information management has become an important indicator to measure the scientific management and modernization of enterprises, and full automation and information of personnel archives management is an important part of information management. The quality of personnel archives management is important for decision-maker and managers of some organizations, largely affect the economic and social benefits of enterprises [1]. Personnel management information is on the basis of the traditional personnel management, which is based on communication network technology, using modern information processing tools, finally realizing the efficiency, networking, standardization, paperless of personnel management. [2].

\section{SYSTEM ARCHITECTURE}

\section{A. Cloud computing}

Cloud computing is the development of distributed computing, parallel computing, and grid computing, which represents an emerging business. Cloud computing is a comprehensive solution that delivers IT as a service. It is an
Internet-based computing solution where shared resources are provided like electricity distributed on the electrical grid. Computers in the cloud are configured to work together and the various applications use the collective computing power as if they are running on a single system[3].

The flexibility of cloud computing is a function of the allocation of resources on demand. This facilitates the use of the system's cumulative resources, negates the need to assign specific hardware to a task. Before cloud computing, websites and server-based applications were executed on a specific system. With the advent of cloud computing, resources are used as an aggregated virtual computer. This amalgamated configuration provides an environment where applications execute independently without regard of any particular configuration[4].

\section{B. System summarization}

The main information modules of personnel management information are: basic personal information management, learning resume management, training resume management, work experience management, professional and technical positions management, meetings management, rewards management, theses management, undertake research management, patents management, works management, technical achievements management, major achievements management, user management, dictionary table management and multi-condition query. These information modules establish a personnel basic database, provide basic data for other systems, and facilitate personnel management staff quickly and easily query related personnel information.

\section{Overall architecture of the system}

This system is a three-tier architecture of the model, provides web services to external systems by B/S structure, meets the distributed access of different users[5]. B/S (Browser/Server) structure is the browser and the server structure, it is with increasing of internet technology, a variation or improved on C/S structure. In this structure, the user interface is achieved via WWW browser, very small part of the business logic is implemented in the front (Browser), but the main business logic is implemented on the server side (Server), and a so-called three-tier structure is formed. This greatly simplifies the client computer load, reduce system 
maintenance and upgrade costs and workload, and reduce the overall cost of the user. The Overall architecture of the system is illustrated in Figure 1.

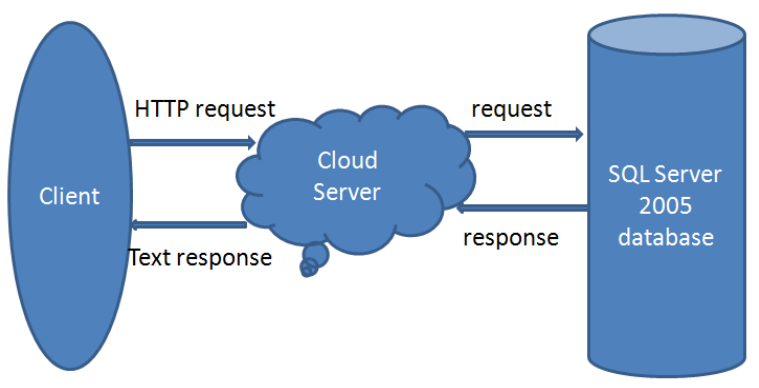

Fig. 1. Overall architecture Figure

The system is divided into four permissions: system administrator, human resources of academy, human resources of institute and common user. Depending on the permissions, the function module and practical function are different from each other. The user rights figure is illustrated in Figure 2.

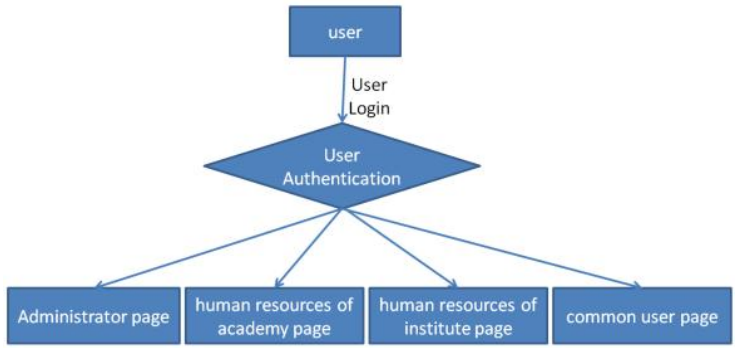

Fig. 2. User rights Figure

\section{SYSTEM DESIGN}

A. System structure design

According to requirements analysis, we design the structure of the system. The system architecture figure is illustrated in Figure 3.

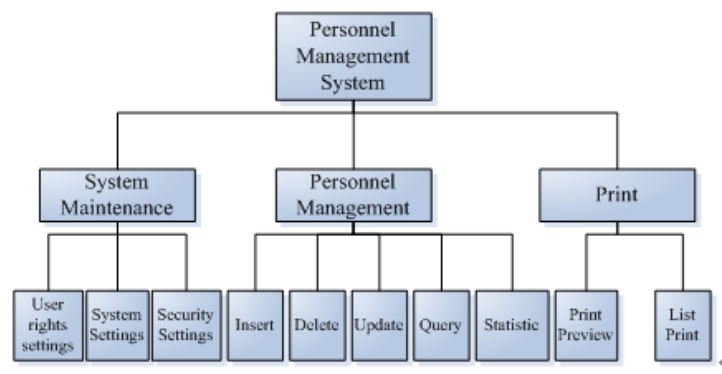

Fig. 3. System architecture Figure

\section{B. Database design}

According to requirements analysis, we design the table of database:

1、 Personnel information table(ExpertBasicInfo).
2、 Learning resume information table

(EducationResume).

3、 Training resume information table

(TrainingResume).

4、Work resume information table(WorkResume).

5、Professional and technical positions information table

(ProfessionalInfo).

6、 Attend meetings table(AttendMeeting).

7、 Obtain awards table(PrizeInfo).

8、 undertake major research table(ProjectInfo).

9、 Papers published table(ThesisInfo).

10、 Works table(WritingsInfo).

11、Patents table(PatentInfo).

12、 Technological achievements table(GainInfo).

13、 Major achievements table(AchievementInfo).

14、Honor table(HonorInfo).

15、Various types of dictionary table : Units dictionary

Table (UnitInfo) and so on.

16. User information table(UserInfo).

17、 Permissions tree table(RightTree).

\section{Presentation layer design}

Presentation layer design of personnel management information system (interface design)_primarily design a series of web interface-, for a variety of operational needs of the user login, online information input, modify, query, etc, then transfer the received information data to the business layer. The interface design mainly uses ASP.NET components, since the limited discourse, which do not show the interface design.

\section{System security design}

Personnel information involves a number of confidential information, and therefore needs to be considered the security of the system. The security of this system is mainly consist of the following aspects:

- Rights management. The system uses role-based access control, associate users and roles, association roles and permissions, thus achieve the logical separation of users and access privileges, greatly facilitates rights management.

- Data encryption technology of database. The basic database of personnel stores some of the key information and sensitive data, therefore the database security is very important. Data encryption is a better way to protect data security of the database. 
- Configuration file encryption, modifies authentication part of Web.Config file which is in root directory of ASP.NET, and sets the authentication mode for an application, as follows:

<authentication mode="Forms">

$<$ Forms name="ASPXAUTH" LoginUrl=Login.aspx

protection="ALL" timeout="30"/>

<authentication>

Configuration files may contain sensitive information, then encryption the configuration file .

- Verification code technology, prevents hackers using illegal program for bulk user login authentication and other illegal. The system uses a graphic verification technology. On the server side, it generates a random number and the random number transmitted to the client. The random number in the user end is in the form of pictures. When users log in to submit, on the server side will compare the random number. If not, it will go wrong, thereby limiting the quantities of user $\operatorname{login}[6]$.

\section{SYSTEM IMPLEMENTATION}

We develop the personnel management information system based on cloud computing by using SQL Server 2005 and ASP.NET combination. SQL Server 2005 database management software is used to save personnel data (.db), ASP.NET is used to develop a front web page, ADO.NET is used as a bridge link between them.

\section{A. ADO.NET technology}

ADO.NET is developed by the ADO(ActiveX Data Objects), it is a connectionless, message-based data access model[7]. ADO.NET is the components of .NET Framework for accessing data. ASP.NET operates database through ADO.NET. As shown in figure 4:

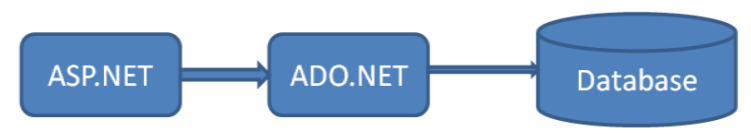

Fig. 4. ASP.NET access the database Figure

One advantage of ADO.NET is that you can operate database offline, applications connect data sources online as long as it requires access to data or update data, it is possible to reduce the application server resource consumption, improve the efficiency of the program.

Figure 5 shows the ADO.NET framework figure, its core is that disconnected DataSet objects can sort the data, search, filter, storage pending changes, as well as browse in a hierarchical data.

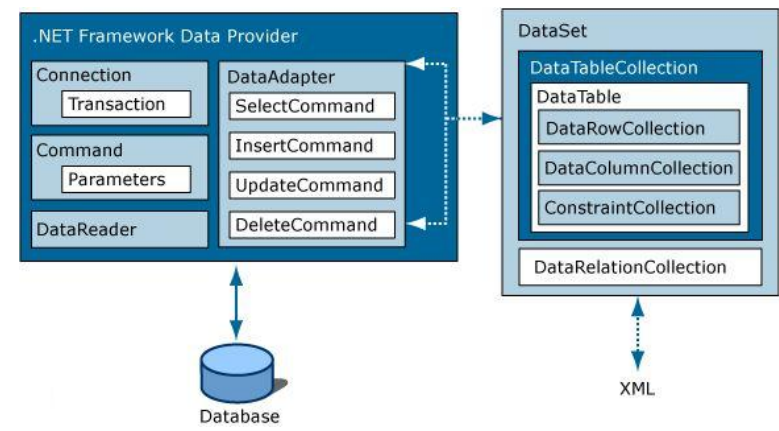

Fig. 5. ADO.NET framework Figure

\section{B. Business logic layer implementation}

Business logic layer of the system is mainly used to do some validation work in order to ensure robustness of the program running. For example, services such as adding data, modifying, querying and so on, will not input an empty string in specified text box, while data in the correct format and data type validation, determines the legality of user rights, etc. Many of the above validation to determine whether the operation passed to the next, try to ensure the normal operation of the program.

\section{Data access layer implementation}

The main function of data access layer is responsible for accessing the database. It achieves operations of Select, Insert, Update, Delete on DataSet .

\section{1) Two connections of SQL Server database:}

a) Mixed mode connection

Use this connection mode must enter a login name and login password.

string myconnection="server=(local);

database $=$ talentmanagement; id $=$ sa;ped $=$ sa"

SqlConnection

conn=new SqlConnection(myconnetion);

b) Windows mode connection

connected mode of windows must set trusted_connection $=$ true.

string myconnection=" server $=($ local $)$;

database $=$ talentmanagement;

trusted_connection=true";

SqlConnection

conn=new SqlConnection(myconnetion);

After the connection is successful, execute operations of Select, Insert, Update, Delete on Dataset

2) GridView control

GridView control is the successor control of the DataGrid. In the .net framework 2, although DataGrid exists, GridView has embarked on a history reception, the trend of replacing 
DataGrid is unstoppable. The function of GridView is similar to the DataGrid, the data source are displayed in the web page.

Following is an example of querying the user information table, which illustrates the using of the GridView control:

Protected void Page_Load(object sender,EventArgs e)

\{

string myconnection="server=(local);

database $=$ talentmanagement; uid $=$ sa;ped $=$ sa"

SqlConnection

conn=new SqlConnection(myconnetion);

string command="select * from UserInfo";

SqlCommand cmd=new SqlCommand(command,conn);

conn.Open();

Sql DataReader dr=cmd.ExecuteReader();

this.GridView1.DataSource $=\mathrm{dr}$;

this.GridView1.DataBind();

dr.Close();

conn.Close ();

\}

\section{CONCLUSION}

This system categories maintenance and integrated queries of personnel information, timely finds out the personnel information they need, facilitates the work of personnel managers, ensures the integrity, timeliness and accuracy of data, improves unit's level of personnel management.

\section{Acknowledgment}

This research was financially supported by Shandong Provincial Science and Technology Project under Grant No. 2014GSF118107,Open Research Fund from Shandong provincial Key Laboratory of Computer Network under Grand No.SDKLCN-2014-04 and Postdoctoral Innovation Special Fund of Shandong Province.

\section{References}

[1] A O, Solomon E H, Omono C E. A Critical Appraisal of Personnel Management System and its Performance in Colonial Nigeria[J]. Asian Journal of Social Sciences \& Humanities Vol, 2014, 3: 2.

[2] Benson L. Personnel management systems and related methods: U.S. Patent Application 13/848,601[P]. 2013-3-21.

[3] Cloud computing privacy concerns on our doorstep[J]. Communications of the ACM, 2011, 54(1).

[4] Beloglazov A, Abawajy J, Buyya R. Energy-aware resource allocation heuristics for efficient management of data centers for cloud computing[J]. Future generation computer systems, 2012, 28(5): 755768.

[5] Su K W, Liu C L. A mobile Nursing Information System based on human-computer interaction design for improving quality of nursing[J]. Journal of medical systems, 2012, 36(3): 1139-1153.

[6] Savaneviciene A, Stankeviciute Z. Relabelling or new Approach: theoretical insights regarding Personnel Management and Human Resource Management[J]. Engineering Economics, 2013, 24(3): 234243.

[7] Want R, Weiser M D, LaMarca A G, et al. System and method for obtaining and using location specific information: U.S. Patent RE42,927[P]. 2011-11-15. 